\title{
Human races are not like dog breeds: refuting a racist analogy
}

\author{
Heather L. Norton ${ }^{1}$, Ellen E. Quillen², Abigail W. Bigham ${ }^{3}$, Laurel N. Pearson ${ }^{4}$ and Holly Dunsworth ${ }^{5^{*}}$ (D)
}

\begin{abstract}
In 1956, evolutionary biologist J.B.S. Haldane posed a question to anthropologists: "Are the biological differences between human groups comparable with those between groups of domestic animals such as greyhounds and bulldogs...?"It reads as if it were posted on social media today. The analogy comparing human races to dog breeds is not only widespread in history and pop culture, but also sounds like scientific justification for eschewing the social construction of race, or for holding racist beliefs about human nature. Here we answer Haldane's question in an effort to improve the public understanding of human biological variation and "race" — two phenomena that are not synonymous. Speaking to everyone without expert levels of familiarity with this material, we investigate whether the dog breed analogy for human race stands up to biology. It does not. Groups of humans that are culturally labeled as "races" differ in population structure, genotype-phenotype relationships, and phenotypic diversity from breeds of dogs in unsurprising ways, given how artificial selection has shaped the evolution of dogs, not humans. Our demonstration complements the vast body of existing knowledge about how human "races" differ in fundamental sociocultural, historical, and political ways from categories of nonhuman animals. By the end of this paper, readers will understand how the assumption that human races are the same as dog breeds is a racist strategy for justifying social, political, and economic inequality.
\end{abstract}

Keywords: Domestication, Evolution, Human variation, Population genetics, Phenotype, Genotype, Racism, Anthropology, Biological anthropology, Anthropological genetics

\section{Background}

Dogs factored greatly into Darwin's conception of evolution (Townshend 2009) and he specifically pondered the similarities of human races and dog breeds in The Descent of Man (1871). As an integral and influential player in Darwin's legacy, evolutionary biologist J.B.S. Haldane posed a question to a group of anthropologists at the Royal Society in 1956 that reads as if it were posted on social media today: "Are the biological differences between human groups comparable with those between groups of domestic animals such as greyhounds and bulldogs...?"

In the U.S., and likely beyond, the human race-dog breed analogy is not merely an academic question about

\footnotetext{
*Correspondence: holly_dunsworth@uri.edu

${ }^{5}$ Department of Sociology and Anthropology, University of Rhode Island, Kingston, RI, USA

Full list of author information is available at the end of the article
}

patterns of variation; today, it factors substantially into the popular debate about whether race is fundamentally biological as opposed to a social construct, and it carries forward an ugly American tradition. Inherent to the analogy is the transference of beliefs about pure-bred dogs onto notions of human racial "purity" (e.g. Castle 1942; Harrington 2009), which helped U.S. legislators pass anti-miscegenation laws in the early twentieth century (Lombardo 1987). In 2016, Mother Jones demonstrated how mainstream and persistent the analogy is when they published their interview with a leading white supremacist who equated human races to dog breeds (Harkinson 2016). The American familiarity with dogs helps make their relevance to human "race" seem natural. It sounds like science, but as we demonstrate below it is not.

Here we investigate how the biological variation among dogs and humans compare and contrast, answering Haldane's question while rebuking the illegitimate appeal to science and the erroneous "logic" of the widespread 
analogy. To start, we compare genotypic and phenotypic variation within and between human groups and within and between dog breeds. After we demonstrate the fundamental biological differences between patterns of variation in the two different species (parts 1,2, and 3), as well as the fundamental distinctions between "race" in humans and dog breed categories (part 4), we discuss the sociocultural significance of this analogy and the importance of its refutation (parts 4 and 5). That is, a goal of this paper is to reveal why equating the category we culturally call "race" to patterns of human biological variation is non-sensical and equating "race" to the categories we know for dogs is pernicious and racist, despite the comparison appearing obvious to many individuals. We counter the seemingly innocent belief that because dogs are distinguishable, on sight, by breed that therefore human racial categories are just as biologically-based. As many readers know all too well, the breed-race analogy sits in close cultural and mental proximity to the noninnocent racism that lowers targeted minorities to the status of nonhuman animals (see Weaver 2013). Readers are urged to consult the vast and rich literature discussing the cultural-historical-political context of categorizing humans, and the social construction of the race concept, including and especially by scientists, some of which we cite throughout this paper (e.g. Sussman 2014; Marks 2012a, b, 2017; Brace 2005; Koenig et al. 2008; and many others). This context is imperative, but that the race-breed analogy persists means that there are individuals who are either unfamiliar with that knowledge or are unconvinced by it, perhaps willfully so.

Here, for the purposes of demonstrating that the race-breed analogy is not supported by science (despite it being used by some as scientific-sounding justification for race-based social injustices), we must use the conceptions of race and breed dictated by the terms of the analogy itself. That is, we will consider the biological variation within and between groups acknowledged by the 2010 U.S. census (United States Census Bureau) and the American Kennel Club (AKC), respectively. The AKC lists 192 dog breeds. The number of dog breeds has varied over time, increasing as institutions recognize new breeds among the some four hundred to a thousand breeds described globally. The five racial categories used most recently by the United States Census Bureau (White, Black or African American, American Indian or Alaska Native, Asian, and Native Hawaiian or Other Pacific Islander) reflect the current perception of race in the U.S. However, the number of human races has varied throughout U.S. history, reflecting the shifting social and political motivations, including slavery and immigration, a fact that highlights the significant ways that race concepts are driven by social forces. Presently, racial categorizations vary across cultures-for just one example, there are at least 18 terms to describe a person's race or skin color in Brazil (Santos et al. 2009).

As noted above and as will be discussed in this paper, "race" is far more than ancestral/inherited DNA and is far more than geographically patterned morphological variation like skin color. But because the analogy between races and dog breeds incorrectly privileges biology over the social and historical factors that have led to the development of racial constructs, here we demonstrate how genetic data fails to substantiate the racial categorizations used in the U.S. today and their equivalence to dog breeds.

\section{Population structure of human races and dog breeds}

A key assumption of the race-breed analogy is that both human "races" (i.e. U.S. census groupings) and dog breeds are formed and structured in similar ways, with each representing distinct groups within each species. If this assumption holds, then one expects to observe both high levels of among-group diversity and low levels of withingroup diversity. Put another way, this predicts that groups (whether races or breeds) are clearly distinguishable from each other while at the same time also being internally very similar. Physical anthropologists have a long history of trying to classify people into groups based on biological traits (for example, skin color, cranial measurements, blood group antigens, and more recently DNA). Notably, such groups often varied depending on the trait studied, the populations explored, and the political motivations of the scientist doing the classifying (reviewed in Marks 2012a, b). Today, anthropologists remain interested in the patterns of variation in these and myriad other biological and biocultural traits. However, their motivations for doing so are to use such information to reconstruct human evolutionary history, and to investigate the biological and sociocultural processes that shape phenotypes, rather than to identify biologically discrete human groups.

Patterns of among- versus within-group genetic diversity can be assessed using various tools and methods from the field of population genetics. For example, both the $\mathrm{F}_{\mathrm{ST}}$ statistic and analysis of molecular variance (AMOVA) allow one to investigate patterns of amongversus within-group genetic diversity. Higher $\mathrm{F}_{\mathrm{ST}}$ values indicate a more structured population (i.e. possessing distinct clusters) while lower values (closer to 0) imply less structure (i.e. possessing few or no distinct clusters, most likely due to higher rates of random mating among individuals). AMOVA allows a researcher to partition the total amount of genetic variation in a sample into different levels. When a large percentage of the total variation 
in a sample can be explained by among-group differences within the sample, this suggests that the sample is highly structured, and composed of distinct genetic subpopulations. Alternatively, when variation among individuals within groups explains a large portion of variation in the total sample of all the groups, it implies a less structured population.

In addition, statistical programs such as structure (Pritchard et al. 2000) use model-based clustering algorithms to place individuals into a predetermined number of groups based on multilocus genotype data, and to estimate the fraction of genetic ancestry that individuals have from each of these groups. Results are displayed graphically, with population groups denoted by different colors. Individuals with ancestry from multiple groups are displayed using multiple colors (see Figs. 1 and 2 for examples and further explanation). It is important to note that structure will always identify the number of groups specified by the user-the program tries to find the best way to allocate sampled individuals into $k$ user-defined groups in a way that will maximize Hardy-Weinberg equilibrium for each group (Bolnick 2008). As such, it is important for users to run structure for multiple values of $k$, and evaluate the statistical likelihood of each of these models.

Structure's results are sensitive to a number of factors, including linkage between loci, Hardy-Weinberg equilibrium, sample sizes of populations, genetic drift, and geographic distribution of populations (discussed in Lawson et al. 2018; Novembre 2016; Bolnick 2008). Further, interpretation of the groups identified by structure as real, "pure" groups instead of statistical constructs runs counter to how evolution works and also runs the risk of reifying old and false biological conceptions of race (Weiss 2018; Weiss and Lambert 2010, 2011, 2014; Weiss and Long 2009). Specifically, such misinterpretations imply that at some point in our evolutionary past there existed a set number of distinct homogeneous

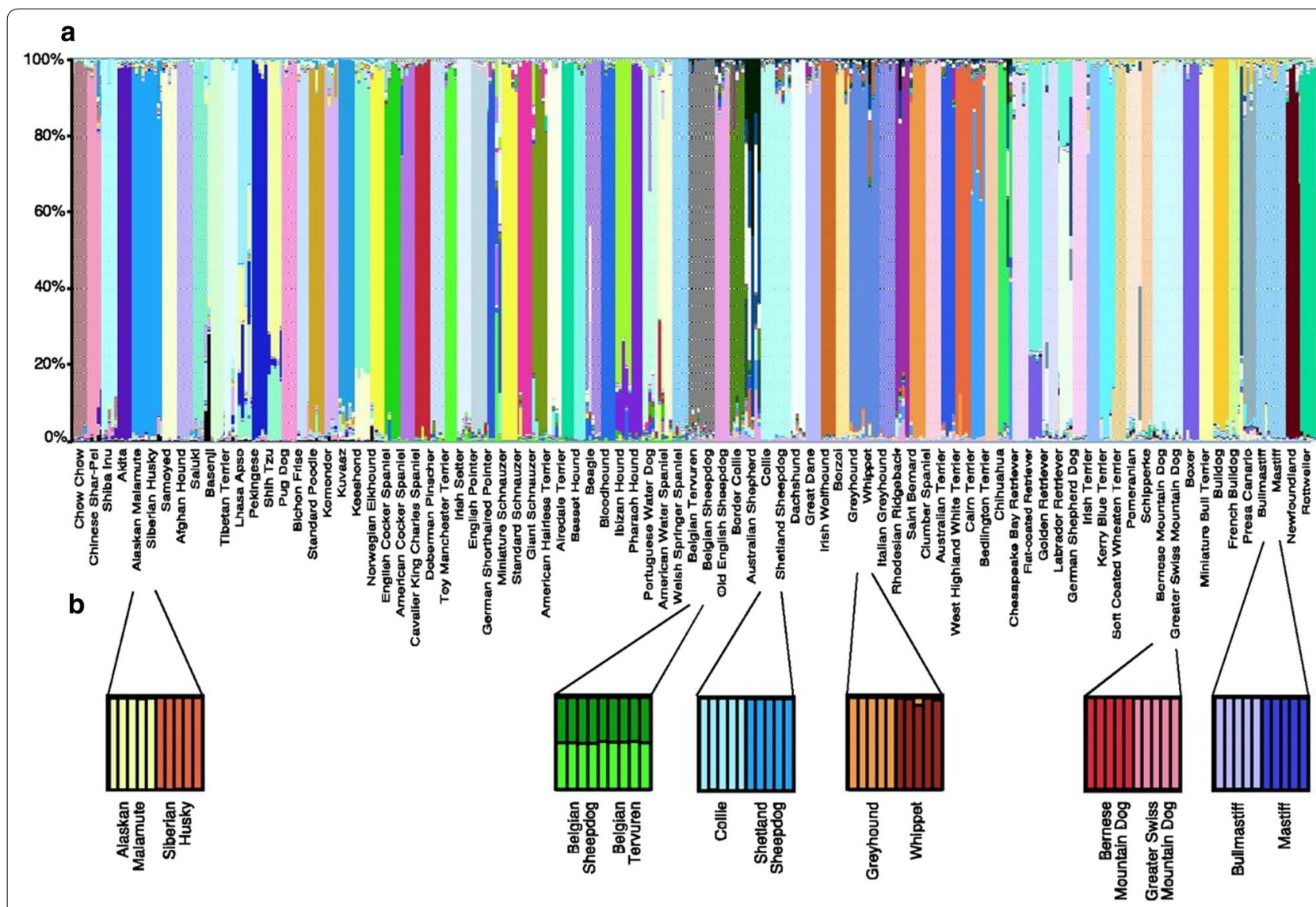

Fig. 1 Clustering assignment of 85 dog breeds by Parker et al. (2004): "seventy-four breeds are represented by five unrelated dogs each, and the remaining 11 breeds are represented by four unrelated dogs each. Each individual dog is represented on the graph by a vertical line divided into colored segments corresponding to different genetic clusters. The length of each colored segment is equal to the estimated proportion of the individual's membership in the cluster of corresponding color (designated on the $y$ axis as a percentage). Breeds are labeled below the figure" 


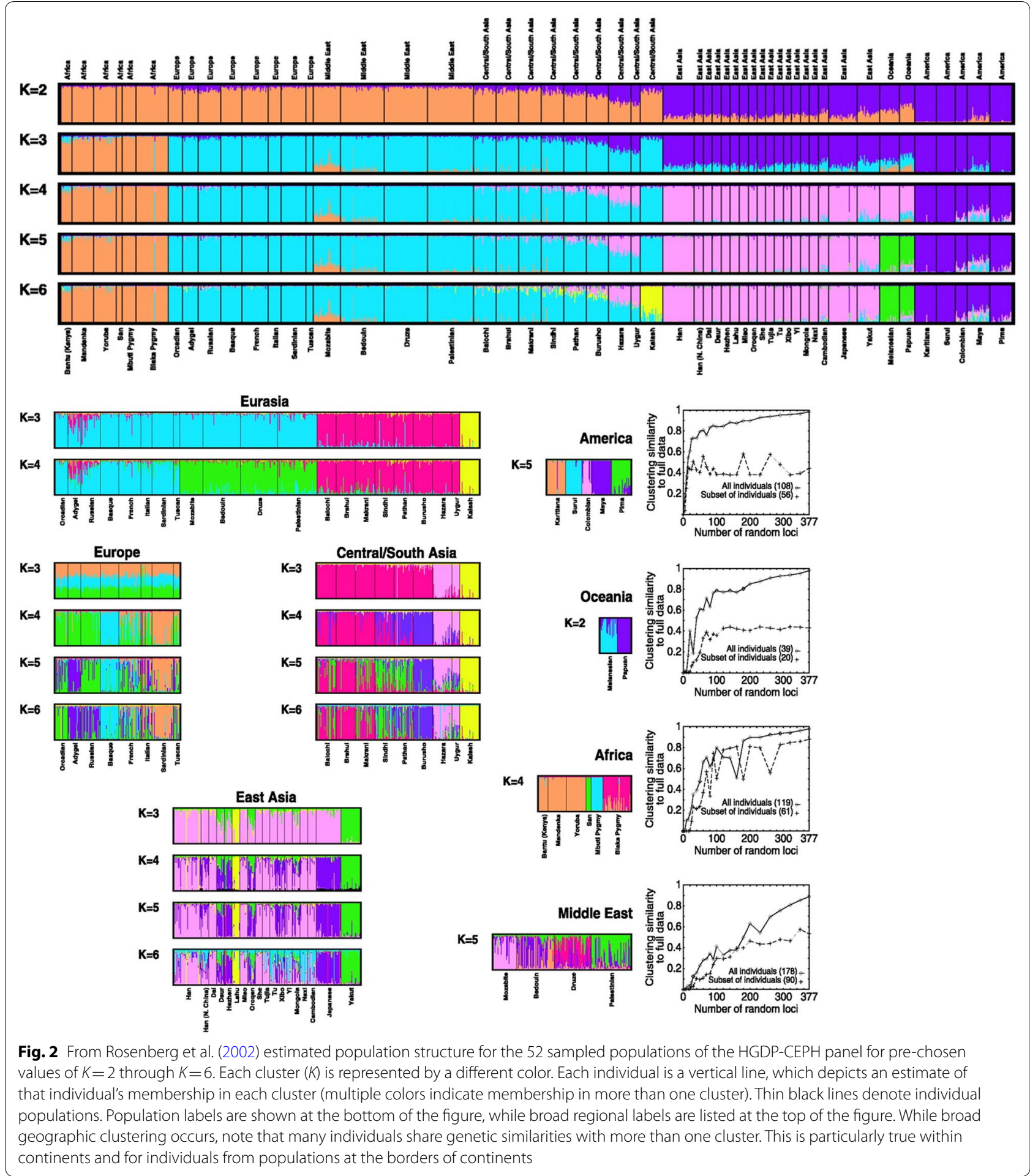

groups, and that modern populations or individuals with ancestry from multiple groups are somehow less "pure". It must be emphasized that no current or past population is homogenous or pure and no living population is any group's ancestral population. As Weiss and Lambert
(2010) point out, these approaches can "describe data as if they reflect true evolutionary history. As-if fictions can be useful as analytic tools if everyone understands they are simply convenient statistical digests. But the phrasing of papers often suggests [without 'imputing to them any 
social racism' (p. 97)] that the typological conclusions are being taken as if they represent actual history." (p. 95).

While the data and results from structure can be misinterpreted in the ways described above, they can be helpful in illustrating if and how genetic variation is shared across groups. Now, let's consider levels and patterns of dog and human genetic variation to see how they compare. In 2004, Parker and colleagues analyzed data from single nucleotide polymorphisms (SNPs) for 120 dogs representing 60 breeds as well as 96 microsatellite loci genotyped in 414 dogs representing 85 breeds. Both STR and SNP data demonstrated low levels of within-breed heterozygosity, indicating that within breed genetic variation was low $(\mathrm{H}=0.313-0.610)$, while $\mathrm{F}_{\mathrm{ST}}$ estimates also indicated high levels of differentiation among breeds $\left(\mathrm{F}_{\mathrm{ST}}=0.33\right)$. These results were consistent with earlier studies looking at smaller numbers of breeds (Koskinen 2003; Irion et al. 2003), and have been supported by subsequent studies of dog population structure and domestication (vonHoldt et al. 2010). In their AMOVA analysis of the 96 genotyped microsatellites, Parker and colleagues (Parker et al. 2004) report that $\sim 27 \%$ of variation among dogs in their sample could be attributed to variation across breeds, with the remainder of the genetic variation explained by within-breed variation, implying that the breeds in their sample are highly genetically isolated from each other.

Parker et al. (2004) then used the program structure to place individual dogs into a predefined number of population clusters. Running structure on overlapping subsets of 20-22 breeds at a time, they observed that the majority of individual dogs could be placed into distinct clusters that corresponded with their reported breed identity (Fig. 1). Using genotype data alone, they correctly identified the breed of $99 \%$ of the dogs included in their sample. Taken together, the low within-breed heterozygosity, high among-breed $\mathrm{F}_{\mathrm{ST}}$, AMOVA, and structure results all present a picture of a highly structured population.

Parker et al's analysis of dog population structure can be compared to an earlier study of human population structure using similar methods (Rosenberg et al. 2002). In this paper, Rosenberg and colleagues utilized allele frequency data from 377 microsatellites genotyped in the 52 populations of the HGDP-CEPH Human Genome Diversity Panel. Rosenberg et al. conducted AMOVA that examined genetic variance components within and among the individual populations of the HGDP-CEPH as well as within and among five and seven broad geographical groupings of these populations. These regional groups can be viewed as generally analogous to continental regions and U.S. census groupings (the sevenregion scheme divides Europe/Middle East/Central Asia into three separate categories). The authors observed that genetic differences among regions accounted for only $3.3-4.7 \%$ of global human genetic variation (much smaller than the $27 \%$ of genetic differences among dog breeds reported by Parker et al. 2004), and that variation within populations accounts for 92.9-94.3\%. Differences among populations within regions accounted for $2.4-2.6 \%$ of the remaining genetic variation. In addition, within-region levels of heterozygosity $(0.664-0.792$; Rosenberg et al. 2002) were notably higher than those observed for dog breeds (0.313-0.610; Parker et al. 2004). This reflects the much greater total genetic variation within human groups compared to dog breeds. These results are comparable to those from other human datasets/populations, including HGDP-CEPH multilocus SNP data (Li et al. 2008). Furthermore, data from The 1000 Genomes Project demonstrates that $\mathrm{F}_{\mathrm{ST}}$ values between continental groups are far lower $(0.052-0.083)$ than $\mathrm{F}_{\mathrm{ST}}$ values for dog breeds (The 1000 Genomes Project Consortium 2015). In sum, these data suggest that a greater degree of global genetic variation in humans can be attributable to variation within local populations, rather than between regional (racial) groups, and that substantial heterogeneity can be found within these groups. This stands in marked contrast to the lower levels of heterozygosity observed within dog breeds and the large amount of genetic variation that can be explained by breed differences.

Rosenberg et al. (2002) also used the program structure to explore patterns of human genetic variation in the HGDP-CEPH dataset (Fig. 2). They found support for a model of six genetic clusters, five of which roughly correspond to the broad continental regions of Africa, Europe/ Middle East/Central Asia, East Asia, Oceania, and the Americas (the sixth cluster corresponded to the isolated Kalash population of northwest Pakistan). While some spuriously interpreted the identification of these clusters as support for a genetic basis for human racial groups (Wade 2014), others identify aspects of these results that are inconsistent with such an interpretation. First, Bolnick (2008) notes that in addition to finding support for the six-cluster model, Rosenberg and colleagues found support for models specifying a larger number of clusters, although the groupings of the 52 populations within those clusters were often inconsistent, suggesting a low confidence in any given clustering of the populations. The existence of multiple clustering models of human genetic variation contrasts the rigid breed-aligned clusters identified for dogs by Parker et al. Second, Rosenberg et al. found that most individuals had membership in more than one cluster, implying that genetic clusters did not represent discrete genetic units. This pattern was particularly noted for humans living near the borders of these geographically linked clusters. This supports a 
distribution of genetic variation that is driven by constant mating among neighboring populations and relatively low levels of genetic differentiation driven almost entirely by geographic factors.

In 2003 Bamshad and colleagues genotyped over 500 people from sub-Saharan Africa, Europe, Asia, and Southern India for $100 \mathrm{Alu}$ insertion polymorphisms and 60 microsatellites. Much like Rosenberg et al., these authors used the program structure to identify genetically determined clusters of populations within this sample. They also attempted to place individuals from Africa, Europe, and East Asia into the correct continent of origin using only genotype data. The authors report being able to do so for $99-100 \%$ of the samples. In this case, a correct assignment meant that an individual was identified as having the greatest proportion of ancestry in the genetic cluster corresponding to their continent of origin. While this might sound like good support for the idea that humans can be assigned to unique and distinct genetic clusters that correspond to continental groups, the interpretation of these results is complex, as outlined by Bolnick (2008). First, structure analysis of the subSaharan African, European, and East Asian samples identified four clusters: Europeans, East Asians, sub-Saharan Africans (excluding Mbuti pygmy populations and three other African individuals), and a cluster consisting of Mbuti and the remaining three African individuals. However, most subsequent analyses were conducted assuming only three clusters (ignoring potential structure within Africa). Second, as noted by Bamshad et al., the populations chosen represent relatively small samples from a limited number of populations that are widely geographically dispersed-the inclusion of people from geographically intermediate regions may have lowered the accuracy of cluster assignment. As an illustration of this, when South Asian samples were included in the analyses, accuracy of cluster assignment for these samples was notably lower (87\%; Bamshad et al. 2003).

Taken together, these comparisons suggest that these continental-based human racial categories differ from dog breeds in two ways. First, levels of within-group (within-"race" or U.S. census groupings) diversity in humans are generally considerably higher than diversity observed within dog breeds, while levels of differentiation among such human groups is lower than observed among breeds. Second, while it is possible to use algorithms such as the one implemented in structure to identify groups of humans that tend to cluster on the basis of genetic similarity (in other words, there is some structure to human genetic diversity as is expected given how humans, like all species, do not mate at random, but over the generations have tended to reproduce with those who live relatively close to them), those clusters tend to be highly porous (individuals may have membership in multiple clusters) and determining the "correct" number of clusters is subjective, even for geneticists. That is, U.S. census groupings are not the only way to impose order on patterns of human genetic variation.

In the comparisons above, we have used the continental population clusters identified by Rosenberg et al. as a proxy for U.S. racial categories. However, it is important to note that racial categories in the U.S. are not simple reflections of geography, nor are these categories applied using definitions of "race" proposed by some geneticists. For example, Dobzhansky [who argued against racial essentialism, as described in Jackson and Depew (2017)], defines races as "Mendelian populations that differ in the frequencies of some gene or gene" (Dobzhansky 1955). While this definition reflects the strong mathematical roots of population genetics (and could be applied in many different ways to different groups, nesting it within that larger, arbitrary social framework for "race"), the use of the term "race" in the U.S. encompasses far more than simple differences in allele frequencies.

Racial categories in the U.S. are drawn, in part, on the western concept of race first described by Linnaeus, which emphasized differences among humans based on geographic, physical, cultural, and behavioral factors. As described in Marks (2016), these categories were heavily influenced by the social, cultural, and political factors of that time. These included extended sea travel by Europeans (traveling great distances by sea tended to emphasize differences in appearance and culture, while land travel highlighted more gradual changes), as well as the strong motivating sociopolitical and economic influences of both colonialism and slavery. From the beginning, racism was embedded in race science. Within the U.S., racial categories (as recognized by the U.S. census) have shifted over time, reflecting concerns about slavery, immigration, hypo- and hyper-descent, and access to resources (Snipp 2003). Alongside that ongoing history, there has been disagreement among geneticists about how human genetic variation is patterned, most famously between Lewontin (1972) and Edwards (2003). For perspective, Marks (2010) wrote,

"What is unclear is what this [disagreement] has to do with 'race' as that term has been used through much in the twentieth century-the mere fact that we can find groups to be different and can reliably allot people to them is trivial. Again, the point of the [biological] theory of race was to discover large clusters of people that are principally homogeneous within and heterogeneous between, 
contrasting groups. Lewontin's analysis shows that such groups do not exist in the human species, and Edwards' critique does not contradict that interpretation." (p. 270)

Other genetics researchers have concluded that human evolutionary history has produced a "nested pattern of genetic structure that is inconsistent with the existence of independently evolving biological races" (Hunley et al. 2009). This perspective complements Livingstone's famous "there are no races, only clines" (1962) statement, which refers to the spectrum of continuous human phenotypic variation we see globally. Two examples of continuous geographic variation in the human species include human cranial shape and size (Relethford 2009) and skin color, a trait strongly influenced by natural selection, showing clinal variation in epidermal melanin moving north and south away from the most intensive UV radiation around the Equator (Gibbons 2014; Fig. 3). Clinal variation across human-defined boundaries like continents refutes clear-cut distinctions between human groups.

If patterns of genetic or biological variation were found to be identical between dogs and humans, or between any other species and humans, that would still not support a biologically-based concept of "race," with or without its foundation for racism. Further consideration of these issues and a demonstration of the link between the biological concept of race and racism can be found in part 4, below. The point here is to show that the scientific sounding basis of the breed-race analogy does not hold up to science and we continue refuting the analogy next, with a comparison of the evolutionary histories of dogs and humans, which are the circumstances that created the observed variation today.

\section{Origins and evolution of biological variation within humans and domestic dogs}

While our understanding of Homo sapiens origins is increasingly complex, the fossil record indicates that all humans alive today trace their ancestry to Africa, roughly 200-500 kya and all hominin evolution prior to $\sim 2$ mya occurred in that region of the world. Genomic studies indicate that all humans descend from ancestors living in Africa whose descendants dispersed around Africa, Europe, Asia, and Southeast Asia. Subsequent interbreeding with late Pleistocene hominins in Europe (Neanderthals) and Asia (Denisovans) within the past 100 kya affected human evolution, uniquely, in those regions (Vernot et al. 2016; Higham et al. 2014; Reich

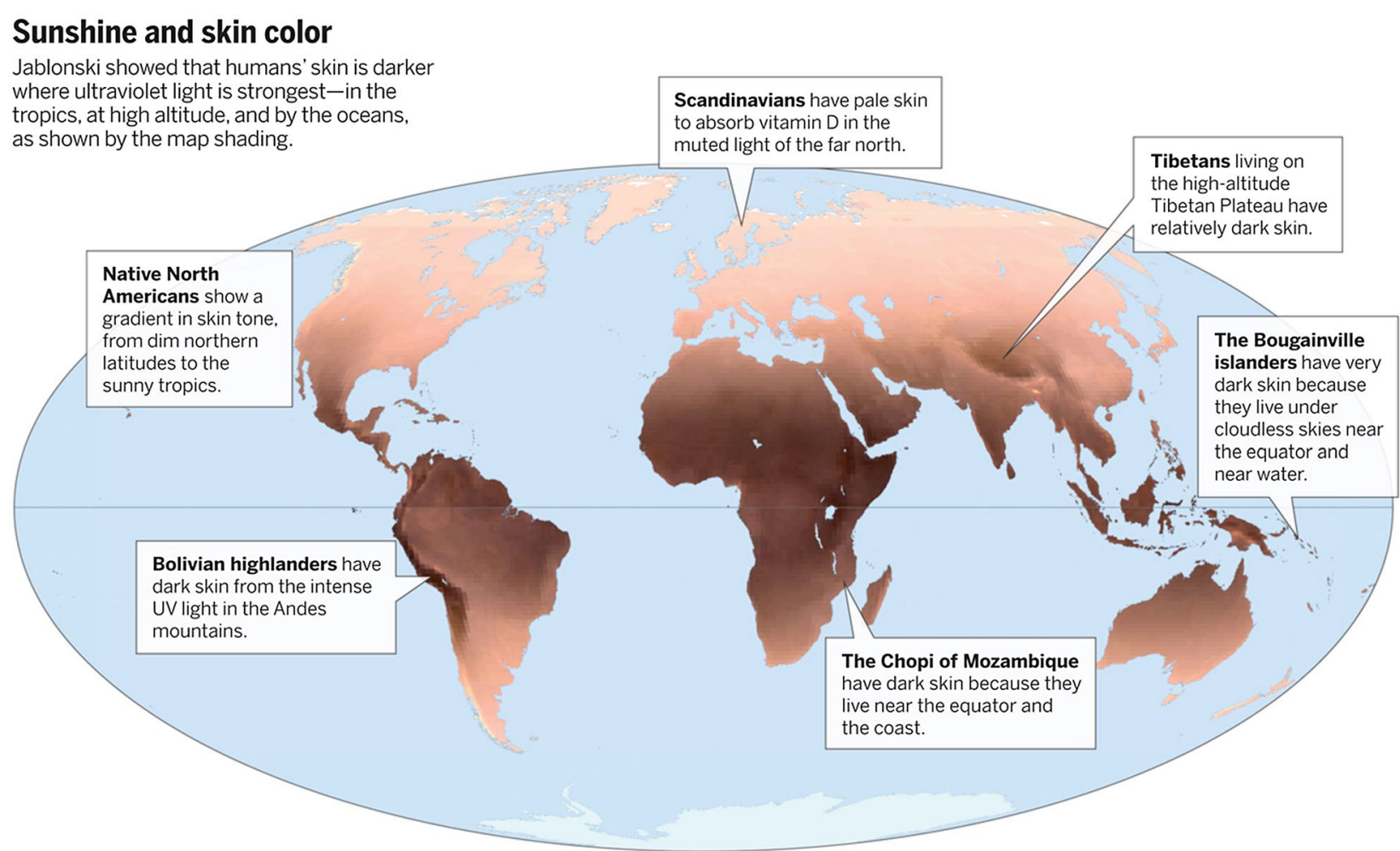

Fig. 3 From "Shedding Light on Skin Color" by Gibbons (2014) 
et al. 2011; Kuhlwilm et al. 2016). Present human biogeographic variation has been shaped by this Pleistocene migration and gene flow, plus more than 50,000 years of subsequent gene flow, genetic isolation, genetic drift, selection, epigenetic change, and coevolution with other species, not to mention culture (Simonti et al. 2016; Dannemann and Kelso 2017; Racimo et al. 2015). As a result of the effects of these different evolutionary forces, while a number of very rare (and usually very young) alleles may be geographically localized, the majority of common genetic variants are not private to a particular continent, and are often shared across multiple regions (The 1000 Genomes Project Consortium 2015). This is because, in contrast with dogs, no modern human populations have ever been completely reproductively isolated over many generations.

Our understanding of Canis lupus familiaris (purebred dogs, mixed breed dogs, and "village" dogs) origins is also growing in complexity. All dogs are descended from ancient wolves (Vilà et al. 1997), but some researchers have advanced a dual origin hypothesis (Frantz et al. 2016) with centers in southern China by 15 kya (Wang et al. 2016) and in Europe between 32 and 18 kya (Thalmann et al. 2013) or 20-40 kya (Botigué et al. 2017). Present biogeographic variation in domestic dogs is the result of all the same mechanisms of evolutionary processes that affect humans, as well as domestication via coevolution, cohabitation, mutualism, and intentional breeding or "artificial selection" by humans.

In village dogs specifically, present biogeographic variation has been shaped by more than 15,000 years of backcrossing and hybridization with wolves, coyotes, jackals, and domestic breeds, plus gene flow, genetic isolation, genetic drift, selection, and co-evolution with humans. Village dogs are more genetically diverse and geographically widespread than domestic breeds (Shannon et al. 2015). While the so-called "ancient breeds" like chow chows and salukis are as old as a few 1000 years, most dog breeds are younger than a few 100 years. Some breeds (e.g. the Bernese mountain dog) arose by hybridizing breeds while others were bred from existing breeds to serve a particular role. At present, no population of village dog is genetically isolated, but every breed effectively is.

Breeds arise due to breeders' extreme control of mating to maximize the presence of desired traits in the next generation of dogs. In this process of artificial selection, dogs are prevented from mating outside their breed and only a limited number of animals are permitted to reproduce within a breed. Some male dogs have sired more than 2500 offspring (Leroy 2011). Further, intense selection on closed populations of limited size (i.e. intense inbreeding) is one of the main reasons why dogs have over 1000 inherited diseases and health disorders (Leroy 2011).

The relatively low levels of population substructure (i.e. low levels of between-group variation) in humans are commonly attributed to our relatively recent origin as a species and the high rates of gene flow between human populations that have spread both neutral and adaptive mutations. It is notable that the origin of modern humans (>200 kya) markedly predates that of dog domestication (20-40 kya). When differences in generation time between the two species are taken into account $[\sim 20$ years for humans $=10,000$ generations over 200,000 years; $\sim 4.5$ years for wolves (Mech et al. 2016) $=\sim 9000$ generations over 40,00 years], it would seem that there has been just as much or more time for substructure to evolve in our own species as has evolved in dogs. That it did not suggests that the strict artificial selection imposed on dogs by humans through selective breeding has had a profound effect on within- and among-breed levels of dog genetic diversity. In contrast, while geographic, cultural, or linguistic features may slow or limit gene flow between human groups, these forces have not resulted in the high levels of genetic differentiation that resulted from artificial selection for distinct and distinguishable breeds of dogs. In accordance with their release from strict selective breeding and artificial selection, village dogs show significantly more genetic diversity and higher heterozygosity than breed dogs (Boyko et al. 2009).

As we saw in the previous section, the majority of genetic variation is shared across human populations. However, in cases where human groups have experienced differentiation via localized circumstances of natural selection (e.g. pigmentation responses to ultraviolet radiation, resistance to pathogens, changes to diet, adaptation to high altitude) we sometimes see convergence on a similar phenotype with independent genetic contributors within the same genes (e.g. lactase persistence in Africa and Europe) or in different genes (e.g. dark pigmentation in groups across Africa and Asia). In contrast, for dogs with similar phenotypes, it is far more often the case that a single underlying mutation is responsible for a shared phenotype. For example, the same mutation at FOX13 causes hairlessness in three dogs with seemingly distinct origins-the Xoloitzcuintli, the Peruvian Hairless, and the Chinese crested-but which all inherited the mutation from a common ancestor, as evidenced by a large, shared haplotype (Parker et al. 2017). Further differences between humans and dogs in the type and distribution of genetic influence on phenotypes are explored next. 


\section{Genotype-phenotype relationships in comparable dog and human traits that vary}

Historically, a key component of "scientific" (read: unscientific) human racial classifications included some combination of physical characteristics, like pigmentation, and body size and shape. These perceptions linger in present-day U.S. cultural conceptions of race, and for many may overshadow the social and political factors that have heavily influenced these concepts. Exploring the biology underlying these physical characteristics helps refute the human race dog breed analogy.

If we consider similar phenotypic traits that also vary in dogs we find that the genotypes underlying these phenotypes involve fewer genes than in humans. This phenomenon is consistent with the lower total genetic diversity within dog breeds compared to U.S. census groupings. Relative simplicity in genotype-phenotype relations, also referred to as "genes of major effect," for some dog traits (Cadieu et al. 2009) has contributed to the ease by which humans have artificially selected seemingly complex traits and the rapid production of entirely new breeds within just several generations. For the ten major dog fur phenotypes (short; wire; wire and curly; long; long and furnishings; curly; curly and furnishings; hairless torso with long hair on head, feet, and tail; hairless torso with short hair on head feet, and tail; and hairless), different combinations of two alleles at only five genes sort them all, with few known exceptions (Parker et al. 2017). In contrast, the seven genes thus far associated with hair curliness in humans can explain only a small fraction of the total variation within or between groups (Eriksson et al. 2010; Adhikari et al. 2016; Medland et al. 2009; Westgate et al. 2017).

The biology of pigmentation may be equally simple in dogs, in contrast to what is well-known for humans. Studies focusing on variation in human skin color within European populations (Beleza et al. 2013; Candille et al. 2012; Sulem et al. 2007, 2008; Valverde et al. 1995) or between Europeans and other populations (Norton et al. 2007; Shriver et al. 2003; Lamason et al. 2005; Quillen et al. 2012), identified 15 genes which explained up to $35 \%$ of the variation in pigmentation in these populations. However, recent studies focusing on non-European populations have identified more than 50 additional loci that affect skin pigmentation within Africa (Martin et al. 2017; Crawford et al. 2017). This reflects the tremendous amount of variation in both skin color and genetics within the African continent and demonstrates that skin pigmentation in humans may be governed by hundreds of loci, including many with complex interactions and minor, but important, effects on phenotypes (Quillen et al. 2019). Additionally, recent work has identified novel mutations contributing to lighter skin pigmentation in
East Asian and Native American populations (Adhikari et al. 2019), further highlighting the diverse genetic mechanisms that influence human pigmentation variation. Due to the shared mechanisms underlying skin and hair pigmentation in humans, a subset of genes implicated in skin pigmentation variation also influence hair pigmentation (Sulem et al. 2007; Valverde et al. 1995; Guenther et al. 2014; Kenny et al. 2012; Nan et al. 2009). However, the genetic architecture of coat color in dogs seems far simpler-currently there are only nine genes known to influence dog coat color and pattern (five of which are associated with coat color specifically) (Kaelin and Barsh 2013).

In terms of stature, human populations vary around the world, and height differs within and among the five races defined by the 2010 U.S. Census. Data from the Centers for Disease Control (Fryar et al. 2016) show differences in the average height of individuals by self-identified racial category, but a much greater amount of overlap. The median white man (of the, on average, tallest racial group among U.S. men) is $177.1 \mathrm{~cm}$ tall (69.7 in.) while the shortest group on average, Asian men, are $170.3 \mathrm{~cm}$ tall (67.0 in.) - a difference of approximately 3 in., or less than 0.2 standard deviations in height among U.S. men. The distribution of variation in stature within human populations is broad and very different from that seen in dog breeds. The height distributions of men in the U.S. overlap such that approximately $15 \%$ of Asian men are taller than the median white man. Both groups overlap even more substantially with black men. (It is also worth noting that the difference in median height between men and women of a single U.S. census group is greater than that between men of any two U.S. census groupings, and the same is true between women.) Consider the tallest (Manute Bol at $231 \mathrm{~cm}$ or $91 \mathrm{in}$.) and the shortest (Muggsy Bogues at $160 \mathrm{~cm}$ or 63 in.) players in the history of the NBA. While they represent extremes of the human male height distribution, Bol is only 1.44 times taller than Bogues.

In contrast, dog breed differences in stature are far greater than what is observed across U.S. census divisions of humans. The median shoulder height in Great Danes $(76 \mathrm{~cm}, 30 \mathrm{in}$.) is four times greater than in Pekingese $(19 \mathrm{~cm}, 7.5$ in.; Stone et al. 2016). When scaled to human height, this would be equivalent to a difference of $470.7 \mathrm{~cm}$ (185.3 in.) or about the difference between an average human and a two-story building. Years of breeding to divergent standards combined with low genetic diversity has resulted in limited and non-overlapping height variation for many breeds (Sutter et al. 2008). Even within dogs in the middle third of the height distribution, like Italian Greyhounds, their top 5\% for height does not overlap with the shortest $5 \%$ of Golden Retrievers. 
Height, like most traits in humans, is extremely complex, meaning it is regulated by a large number of genes (the vast majority of which show nearly identical variation across all human populations) plus environmental factors. It takes more than 400 genetic loci to explain only half of human height variation (Wood et al. 2014), but for dogs, only six major genetic loci explain roughly $50 \%$ the variation in size between breeds (Chase et al. 2002; Jones et al. 2008; Rimbault et al. 2013; Sutter et al. 2007). Considering dogs, one haplotype in IGF1 explains $47.6 \%$ of the variation in height, with a single haplotype variant of IGF1 shared across all small dog breeds (of 14 small and 9 giant surveyed; Sutter et al. 2007).

These differences between humans and dogs in the genetic complexity and the diversity of their traits are due to the distinct impact of artificial selection on dogs. Human genetic variation has been shaped over many generations by relatively weak natural selection on most traits, including height. For example, natural selection on height may occur in certain climate conditions where being taller or shorter may amount to some thermoregulatory or metabolic boost to reproductive success. However, even in populations where height (or skin color or any other such variable trait) is under selection, the majority of individuals across the phenotypic spectrum will still reproduce and pass their genes on to the next generation. Furthermore, the accumulation of new genetic mutations, random fluctuations in trait and genetic variant frequencies due to genetic drift, and the introduction of new alleles into populations via gene flow all dilute natural selection's ability to drive large differences in phenotypes or genotypes between populations. As a result, human populations are genetically very similar to one another with overlapping phenotypes. In contrast, modern purebred dogs exist almost entirely due to artificial selection; their mating is controlled by humans to produce offspring with desired traits. To do this, animals with rare genetic mutations, like those with the dwarf variant of IGF1, are bred together for several generations, acting against the natural accumulation of genetic variation (i.e. evolution by anything other than artificial selection) within the breed.

Dog breeds seem to be so distinct from one another in many conspicuous traits because, relative to human groups, they are. This is true in terms of the extreme differences in physical traits seen between dog breeds, whereas U.S. census groupings overlap in terms of all physical traits, and it is also true with regard to the underlying differences in the genetic architecture that determines these traits.

There are clear and important biological differences between the categories of U.S. census racial groupings and dog breeds and how they relate to overall variation in their respective species, including population structure, genotype-phenotype relationships, and phenotypic diversity. These contrasts are unsurprising given how artificial selection has shaped the evolution of dogs, not humans and given how "race" cannot be reduced to patterns of human biological variation, which is discussed next.

\section{The sociocultural and political construction of race}

Critics will fault this paper for constraining "race" to only the five groups acknowledged by the U.S. Census. But such criticisms only illustrate the subjective, sociocultural construction of the categories humans define as race. While definitions and perceptions of racial categories vary person to person, culture to culture, and throughout time, dog breeds are strictly defined in their breed standards. For example, here is the Portuguese Water Dog (Fig. 4):

"General Appearance: Known for centuries along Portugal's coast, this seafaring breed was prized by fishermen for a spirited, yet obedient nature, and a robust, medium build that allowed for a full day's work in and out of the water. The Portuguese Water Dog is a swimmer and diver of exceptional ability and stamina, who aided his master at sea by retrieving broken nets, herding schools of fish, and carrying messages between boats and to shore. He is a loyal companion and alert guard. This highly intelligent utilitarian breed is distinguished by two coat types, either curly or wavy; an impressive head of considerable breadth and well proportioned mass; a ruggedly built, well-knit body; and a powerful, thickly based tail, carried gallantly

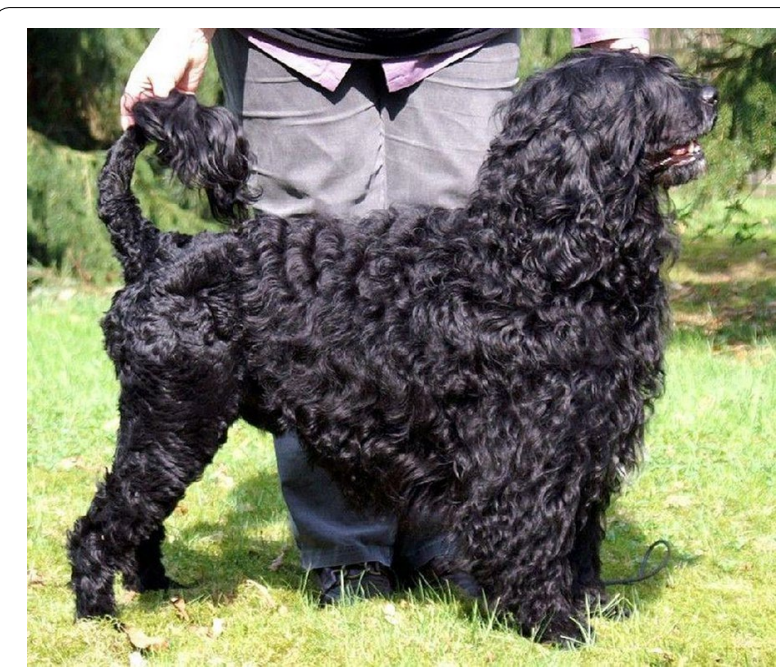

Fig. 4 Portuguese water dog (and limbs of human) (Source: https:// en.wikipedia.org/wiki/Portuguese_Water_Dog) 
or used purposefully as a rudder. The Portuguese Water Dog provides an indelible impression of strength, spirit, and soundness."

All AKC breed standards include physical and behavioral traits, and describe an ideal condition. Written by "parent clubs," dog breed standards describe the champion individual within a given breed. But, within the hierarchical framework of the Great Chain of Being, the earliest descriptions of human "varieties" emphasized not the champion individual but the champion race (Brace 2005). For physician and anatomist J. F. Blumenbach, Georgians or "Caucasians" represented "the closest approximation of God's intent for human form, and other human populations...departed from that manifestation of the ideal" (Brace 2005, p. 46). Eventually Blumenbach's favorite race became "white." Recently some leading scientists and scholars published a statement titled "Taking Race Out of Human Genetics" that included: "Phasing out racial terminology in biological sciences would send an important message to scientists and the public alike: historical racial categories that are treated as natural and infused with notions of superiority and inferiority have no place in biology" (Yudell et al. 2016). In that piece the authors challenge researchers to consider a paradox first noted by Dobzhansky (1962): while race can be a tool to elucidate human genetic diversity, it is a blunt implement that does a poor job of explaining actual relationships between ancestry and genetics. Yudell and colleagues charge researchers and scientific societies to think critically about, and to justify their use of, particular categories to describe human diversity.

Careful consideration of the terminology used in biomedical studies forces both scientists and the public to more clearly understand the questions being asked and the variables used to do so. For example, in some cases using "race" as a variable may be important, especially when exploring how social discrimination, structural racism, and other socially determined factors may be responsible for health disparities. In other cases using "race" may simply obscure important variation within these socially-defined categories that can have significant medical implications (Yudell et al. 2016). The goal is not to ignore patterns of human biological or genetic diversity, but rather to identify new methods to explore these patterns that do not reproduce the harm caused when human biological variation is treated as a mere synonym for racial categories built on the hierarchical organization of people. "Race" is the ranking of biological variation, and whether one race is superior to another is not a scientific or biological issue, which is perhaps why claims of racial superiority or inferiority are so often countered with denunciation of race as a meaningful biological concept and with assertions that its significance is social (Smith 2018).

American history provides more context for the social construction of "race." On the contemporaneity of the establishment of the AKC and the unveiling of the Statue of Liberty, both in the mid 1880s, Harrington (2009) writes how, "the embrace of purebred dogs coincided with the scorning of immigrants," and, "at the height of nineteenth-century immigration, when Irish, German, Italian, Jewish, and other so-called 'races' kept arriving, a purebred dog was not a mongrel, much as someone born in the United States-read a white Anglo-Saxon Protestant-was not an immigrant." Harrington further writes how, "this growing popularity of purebred dogs coincided with a revival of nativism, the movement of 'pure' Americans of the 1840s and 1850s," and likens the "Fitter Family" eugenics contests of the 1930s to AKC dog shows which had become tradition (Harrington 2009). About that time, in 1924, the state of Virginia passed the "Racial Integrity Act," also known as a law against miscegenation (etymologically referring to the mixing of biologically distinct taxa), which prohibited marriages between whites and nonwhites with few exceptions. The rhetoric that swayed the Virginia legislators was steeped in the racebreed analogy, particularly with the concept of "mongrelization." The arguments in favor of anti-miscegenation laws appealed to, and yet also misrepresented, the biological and genetic sciences for support of what were clearly racist political views fearing the disappearance of the white race (Lombardo 1987). Likewise, current arguments that appeal to science to push the "reality" of biologically-based human race, or "race realism," are key to white supremacist politics.

In resisting the scientifically historical idea of race where separate human groups were ranked hierarchically, C. Loring Brace famously called race "a four-letter word." This complex sociocultural-historical understanding of race (as opposed to significantly biologically based) is shared across anthropology and beyond and is understood to be a driving force of sociocultural, health, education, economic, and political inequality and inequity. Emphasizing the sociocultural construction of race in no way diminishes the reality of race as a powerful phenomenon. As Torres and Colón (2015) write, "human biological diversity does not have to be in opposition to constructivist notions of race. Rather, racial experience is emphasized as an embodied experience that is as real and as valid as biological variation." Racism can have damaging consequences on human health and well-being (Gravlee 2009; Gravlee et al. 2009; Sims et al. 2012; Boulter et al. 2015; Quinlan et al. 2016). Yudell et al. (2016) wrote that they "acknowledge 
that using race as a political or social category to study racism and its biological effects, although fraught with challenges, remains necessary. Such research is important to understand how structural inequities and discrimination produce health disparities in socioculturally defined groups."

Both Haldane's question and the pop culture comparison of human races to dog breeds needle at the debate occurring outside of anthropology, and largely outside of academia, over the biological basis for race. These discussions are heavily influenced by the historical conception in science, biology, and anthropology of "race" as being synonymous with (or an acceptable term for) variation in human biology at the group or population level, but that view no longer holds. Within contemporary anthropology there is near consensus that "race" is more of a social construct and, thus, a sociocultural concept than it is a biological concept. According to a survey by Wagner et al. (2017), the majority of professional anthropologist respondents (totaling 3286) disagreed with the following statements: "The human population may be subdivided into biological races" (86\% disagreed); "Racial categories are determined by biology" ( $88 \%$ disagreed); "Genetic differences between racial groups explain most behavioral differences between individuals of different races" (95\% disagreed); "Most anthropologists believe that humans may be subdivided into biological races" (85\% disagreed). Here is a glance at the orientation within that anthropological majority:

"There is a lot of confusion over what we mean when we say race is a 'construction.' Much of the problem involves the fact that in order to rebut scientific racism publicly, we are often obliged to accept the dichotomy of 'nature' and 'culture' that we now realize to be an oversimplification. But since that dichotomy remains a fixture of popular science, and of public discourse, we often have to say, 'No, it's the opposite; it's culture'-when we would really like to say something rather more nuanced. To a first approximation, then, we mean that, unlike a naively regarded fact of nature, which is presumably there to be observed and transparently understood, race is a product of history; and although it is often associated with variation in biological form, it is inherited according to cultural, not biological, rules. And thus, rather than seeing race as a simple product of nature, it is better understood as a product of "nature/culture," the ascription of arbitrary cultural meaning to patterns of human diversity, often in defiance of the biological patterns themselves." (Marks 2017; p. 28)
"Not being a formal scientific concept, a human race is largely not accessible to the scientist. It can only be grasped through the humanities: historically, experientially, politically. [...] Race is not differencebecause all human groups differ from each other, as do all human beings. Race involves imposing some cultural patterns upon human differences." (Marks 2017; p. 106)

"The contribution of anthropology... is to acknowledge the impossibility of studying humans as if we were not ourselves human and to reconceptualize the project as necessarily a biocultural one, infused with cultural values of greater or lesser transparency, but no less scientific for it. [...] The act of articulating and examining the basic assumptions that go into the production of knowledge is often called reflexivity and is one of the hallmarks of contemporary anthropology." (Marks 2012b; p. 96)

"People's imposition of racial categories on, not to mention racist treatment of, each other is a culturally determined and ultimately somewhat arbitrary attempt to make sense of our species' variation in categorical terms. Troubles arise when social predilections lead us to mistake cultural facts for biological ones and vice versa."(Weiss and Fullerton 2005; p. 167)

"Race is a sense-making system imposed upon the facts of difference. Races are not merely human divisions, they are politically salient human divisions. All classifications exist to serve a purpose; the purpose of a racial classification is to naturalize human differences-that is, to establish important categories and make their distinctions appear to be rooted in nature, rather than in history or politics." (Marks 2010; p. 271)

The Portuguese Water Dog demonstrates how entire AKC dog breeds are painted with personalities, like "strength, spirit, and soundness," that individual humans do not even necessarily share with their immediate family members. Yet, dog breeding standards influence assumptions about hard-wired behavior characterizing and differentiating human groups. The jump from clustered physical variation to the assertion of superior and inferior, biologically-based behavioral variation at the group level is the crux of the matter. It is why Haldane's question is so much more than an academic curiosity and why the pop culture analogy equating race with breed demands refutation. 
Arguments in support of the biological basis or "reality" of race are often thinly veiled arguments for a significantly genetic basis behind perceived behavioral differences between races (Sussman 2014). Though it is decades old, the "logic" of this argument or line of thinking, particularly when it relies on the dog breed analogy, is easily gleaned from social media: If one can tell a Dalmatian from a Mastiff and one can tell a person of one race from another race just by looking at them, and if behavior is bred into dogs to a degree that distinguishes breeds too, then genetically-based behavior also distinguishes human races and, thus, a person's intelligence or criminality (etc.) can be predicted by their ancestry.

From this mistaken perspective, the notion of race as a social construct is seen as absurd and so is down-playing the biological basis for race, because to do so is to be willfully stupid, ignorantly anti-science, or brainwashed by a politically correct denial of reality. (Hence, the "race realists" who talk of taking the "red pill," an allusion to the film The Matrix where a person frees himself from living a false reality.) Consequences of that false framework include support for eugenics (past, present, and future), racial segregation of schools, justifying status quo institutional oppression, white nationalism, white supremacy, other forms of racism, and defunding social, environmental, economic, and health programs that counter racism's effects.

When present, this "logic" of the race-breed analogy is not always boiled down to one sentence, like that above. For example, in their influential book "Race: The Reality of Human Differences" Sarich and Miele (2004) advance the race-breed analogy throughout. First, they establish that medical approaches to both human and dog disease share similarities; individual dogs and humans can be sensitive to different drugs and this is sometimes due to inherited genetic variants, which means that the risk varies between dog breeds and between human races. Then, they ease into a discussion of an experiment where a scientist noted individual behavioral differences among several puppies of different breeds. They quote this scientist to have said, "A breed of dog is a construct zoologically and genetically equivalent to a race of man." This leads the authors into an enthusiastic discussion of observed behavioral differences among human babies of different races, which is immediately followed by acceptance of the genetic basis for the racial differences in IQ made famous by The Bell Curve. These pages are then capped by a definition of races as "populations, or groups of populations, within a species, that are separated geographically from other such populations or groups of populations and distinguishable from them on the basis of heritable features" (Sarich and Miele 2004; p. 207) which may sound like a neutral, objective, and scientific approach to classifying human variation except that their book wielding the racebreed analogy betrays otherwise.

The false "logic" about ancestry, race, and human behavior breaks down when one questions the assumptions. First of all, as we have shown, the dog breed-human race analogy is not biologically sound-it assumes race as a natural biological category of humans, a priori. Second and inextricably related, the analogy denies sociocultural context, both past and present. What is more, it includes unquestioned and largely unfounded assumptions about genetically-determined and predictable human behavior.

Scientists are still discovering whether and how dog behaviors are breed-specific and, when they are, how heritable they are. To be clear, a trait's heritability is an estimation of how much of its variation in a population is determined by genetic variation in that population; heritability is not synonymous with its determination or predictability in an individual based on that individual's DNA. There is much known but also much more to learn about what else influences behavioral variation among dogs like weaning age, diet, and other conditions during development. A recent meta-analysis of the heritability of dog behavior concluded that not only are breed standards poorly aligned with the actual behaviors of the breeds they aim to define, but they describe behaviors with little genetic component in the first place (Hradecka et al. 2015). While dog behavior does develop out of inherited (as well as environmental) influences, "breed standards are largely unsubstantiated, for most breeds that have been studied" (Mehrkam and Wynne 2014). These meta studies emphasize that variable behavior within breeds is often overlooked. They also highlight how difficult it is to operationalize behaviors like aggression and intelligence and how difficult it is to measure and compare intelligence in dogs; some dogs solve problems thanks to their relatively heightened senses of smell, while for others it is thanks to their higher energy that keeps them active long enough to solve the problem by chance (Mehrkam and Wynne 2014). Right now, blanket, authoritative and popular claims like "it is obvious that breed differences in behavior are both real and important in magnitude," (Scott and Fuller 1965) supports more stereotyping than the existing evidence deserves.

In the zeitgeist, scientific enthusiasm for genetics has encouraged genetic essentialism, which is the tendency to consider genetic outcomes to be immutable and determined, to prioritize the influence of genes on complex outcomes, to view groups with shared genetic heritage as homogeneous and discrete, and to view genetic outcomes as the most natural and even to be the most morally acceptable (Dar-Nimrod and Heine 2011). This view is encouraged by the frequent confusion of the deceptively complicated scientific concept of "heritable" traits and 
their mistaken translation into being "genetically determined" rather than being polygenic, context dependent, environmentally influenced, and unpredictable in individuals due to their probabilistic nature. Genetic essentialism, where genes are synonymous with essence, is fertile ground for beliefs that meaningful, distinctive individual behaviors have a predictive individual biological basis even in the absence of any identified genes. Variation in human behavior has its roots in both complex genetic and non-genetic factors. Claims that such factors, or their interactions, map neatly onto geographically and socially constructed human groups and can be used to predict behavioral traits associated with such groups, or of an individual member of a group, are not scientifically supported. As Sussman (2014) said about the one behavioral trait that is usually the focus of these discussions, "The idea of a unitary purely genetically based intelligence and of biologically distinct races among humans is as outdated scientifically as the ideas that the earth is flat or that it was created in 4004 B.C." (p. 305)

Finally, Darwin's scenario for the evolution of human intelligence in Descent of Man (1871) pitted human groups against one another, with natural selection ratcheting up intelligence in the dominant groups through time. Hierarchical ranking of human races is also inherently competitive, which is just one reason why outdated and overly simplistic conceptions of evolutionary biology have historically paired with racism, and still do. Within this racist framework, hindsight paints the dominant group as the more genetically intelligent and naturally selected one, justifying its dominance with perceived biological superiority. While it is true that natural selection occurs differently in different lineages and populations, it is no longer dogma ( $>150$ years since Darwin) that natural selection causes divergence due to competition between populations. In many cases, perpetual mutation and drift are enough to explain evolutionary divergence (Hedges et al. 2015).

In a contemporary discussion among philosophers about the biological (also termed "scientific") basis for "race," there are claims that clustered human variation demonstrates the reality of a biological concept of race, and that, further, this supposed reality neither encourages nor partners with racism (Hardimon 2012; Kaplan and Winther 2014). These are carefully worded discussions-based on past and present mainstream evolutionary biology - with one major exception: by insisting that "race" applies to patterns of observable human biological variation, these discussions ignore the sociocultural meaning of race, its historical context, and its political consequences like social and economic inequality. They suppose that "race" is eligible for human taxonomy, but mainstream American culture shows otherwise. "Race" has evolved into a concept that supersedes biology and therefore it cannot also apply as a strictly biological concept. After a racist history of science and a racist history of knowledge production generally, we know that "race" does not exist without racism. As McLean (2019) has described it, there are "co-constructive relationships between historically contingent political processes and the biology of humans." "Race" is, in its essence, about human bias and always has been. If, hypothetically, race was ever to succeed as a wholly objective and neutral biological concept for humans, it lost its chance because so much racist science led us to this socially constructed state of "race" today. About that racist science Zack (2010) writes, "There is a self-revised scientific history of ideas of race, but that is not the same thing as a scientific foundation. The need for such a foundation or some intellectual justification for the enslavement of Africans and the oppression and exploitation of indigenous peoples during the period of European colonization and its subsequent racisms-without question motivated belief in human races [as real and important, biologically differentiated types of humans]." (p. 880)

\section{Biology education, "race," and racism}

People, scientists and nonscientists alike, are susceptible to the same biased thinking and assumptions as they make sense of human biological variation and human social, economic, and political inequality and the intersections of those phenomena. Over 30 years ago, biology educator, Vance (1987) described this problem and how educators were complicit. He argued that scientists and science educators are racist if they are not actively facing the racism that appeals to science. He wrote, "Education in biology has a major role to play in establishing a framework where enquiry can challenge racist images and practices-not least because these may be based on ideas which appear to have scientific justification, and permeate biology texts." He also wrote that, "There is need for a biology curriculum more appropriate to the needs of the pupils, the more politically aware of whom may well feel that learning the classical biology curriculum is tantamount to colluding with racism." And, further, "the content of the curriculum has never been politically neutral. Through engaging in anti-racist education, biology teachers begin to realize that their role in society has always been a political one" (Vance 1987).

Science educator Brian Donovan (2017) is attempting to engage exactly as Vance suggests with junior high school biology students. Based on theory and experimental research, he built two models of the causal relationship between genetic beliefs about group difference, essentialism, and prejudice that align with the "logic" we described, above, that folks glean from pop culture. 


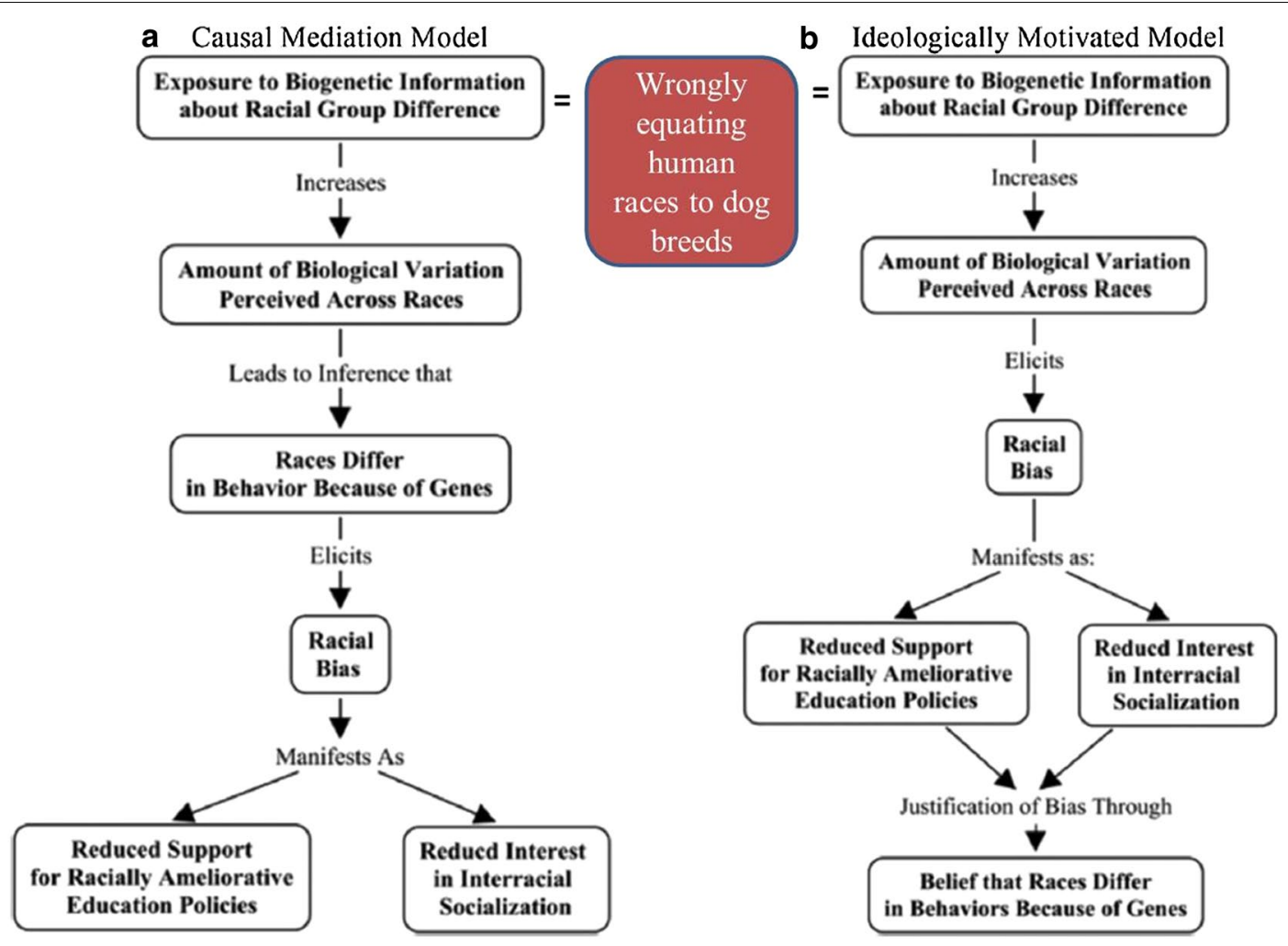

Figure 1. Causal mechanisms. Models A \& B represent possible mechanisms by which biogenetic information about race affects: (i) perceptions of biological variation across races; (ii) genetically deterministic thinking about racial differences in behavior; (iii) interest in cross-racial social contact; (iv) educational racial policy attitudes.

Fig. 5 Figure 1 from Donovan (2017), but with our addition of the red box

Donovan's models are illustrated in Fig. 5 and they are the hypotheses he tests with his educational research.

By editing some human biology content for junior high school students to include racial terminology or to exclude it entirely, Donovan (2017) has found that students learning in what he calls the "racial condition" like that commonly found in textbooks perceived proportionately more biological differences between races and were more essentialist in their thinking after experiencing that curriculum. He also found that they were less interested in socializing across racial lines and were more opposed to policies aimed at reducing racial inequalities in education. He found that "students in the racial condition inferred from their curriculum that if races differ in genetic disease prevalence or skeletal structure, then they probably also differ cognitively and behaviorally because of genetics." As a result Donovan concluded that "repeated exposure to racial terminology in the biology curriculum could be considered a risk factor for the development of belief in [a] genetic [basis for] racial inequality." Like Yudell et al., it's not surprising that Donovan reacts to ideations that perhaps we should remove racial terms altogether from biology: "The problem is not that racial terminology is in the biology curriculum, the problem is that the biology curriculum does not teach students that it is incorrect to infer that races differ behaviorally for genetic reasons on the basis that they differ medically for genetic reasons. [...] the biology curriculum could teach students that racial inequality is not the inevitable product of genes. But, if it does, it should also teach students that inequality can be sustained when people are led to believe that racial difference is genetic."

We take Donovan's words here as a directive when he wrote, "If repeated exposure to racial terminology in biology causes increases in bio-behavioral essentialism and prejudice because it leads students to perceive too much variation between races, then perhaps teaching students about the low amount of variation that actually exists across races will decrease racial bias." With some colleagues, Donovan went on to test that hypothesis, and found that teaching students about genetic variation between U.S. census groupings significantly reduced their prejudice (Donovan et al. 2019). In this light, it is encouraging to see professional organizations, such 
as the American Society of Human Genetics (ASHG) and the American Association of Physical (Biological) Anthropologists (AAP/BA), affirming their commitment to improve public genetic literacy in an effort to address misconceptions about genetics, ancestry, and "race", particularly how such knowledge is misused by white supremacist agendas (ASHG 2018; AAPA 2019).

The existence of the erroneous human race-dog breed analogy suggests that there may be unintended negative consequences of using artificial selection as a model for teaching natural selection. Since artificial selection can produce relatively discrete between group variation and low heterozygosity in a short period of time, perhaps models of artificial selection as teaching tools are inappropriate for middle or high school biology education. For example, these models could skew students' perceptions of what real biological variation would look like if produced by other evolutionary processes (genetic drift, migration, dispersal, isolation by distance, selection, nonrandom mating, etc.). Perhaps the answer is not to take artificial selection out of curricula (because dogs, cats and other familiar organisms make for engaging pedagogy), but to explicitly and rigorously juxtapose it against the rest of evolution. For example, hands-on activities that explore the different ways that evolutionary forces such as selection, gene flow, and drift (e.g. Lee et al. 2017) can affect population variation can be used as a productive starting point to contrast the effects of natural and artificial selection.

\section{Concluding remarks}

This paper bridges academic literature and popular culture. In reaction to notions of race as a "social construct," non-experts may feel justified in holding the opposing belief that race is just biology. Not an insignificant proportion of Americans refuse mainstream academic knowledge; our paper offers a way forward for those caught up in that culture regarding race. This paper is not primarily for the fanatics who are unlikely to change their views, but instead it is for onlookers who might be so unfamiliar with these issues that they are either susceptible to unscientific and/or racist thinking or they are under-equipped to refute it. The dog breed-human race analogy is destructive; if folks see how it does not stand up to biology, then maybe they will better understand the complexity and significance of race. Several decades ago, well before most of the research we cited here was possible, Montagu (1942) covered familiar territory:

"Man has bred dogs for certain temperamental qualities useful in the hunt for many centuries. The Irish setter, for example, is always red-haired, but his red hair has no connection with his temperamen- tal qualities. The Irish setter has the same kind of temperament as the English setter, but the hair color of the English setter is white and black. The only difference between the white, the black, the white and black, and the red setters is in their coat color; there are no significant differences in their mental or temperamental qualities. No one ever asks whether there are mental and temperamental differences between white, black, or brown horses-such a question would seem rather silly. When, however, it comes to man, the prejudice of anyone who has ever made the statement that skin color is associated with mental capacity is accepted as gospel. For such an assumption there is about as much justification as there would be for the assumption that there exist substantial differences between different color varieties of setters. We know this to be false concerning setters only because we have paid more unprejudiced attention to the mental qualities of dogs than we have to those of human beings." (1942; p. 92-3)

Though we have no way of predicting whether what we have presented here will make an improvement ["as if all we had to do (refute racists) would be to teach them some population genetics" (Marks 2010; p. 272)], we felt compelled to try. Scholars and critics may assert that because science has a history of encouraging racialism, scientific racism, and racist appeals to science, then science should step aside in this endeavor. But we believe that racist appeals to science deserve scientific rebukes, at least as one kind of strategy among many.

While we have attempted here to address one very specific belief about human variation, it is embedded in widespread, biased assumptions about dogs and within a dauntingly complex history of science and its sociocultural consequences. Anthropologists, evolutionary biologists, geneticists, scientists, scholars, academics, teachers, writers, journalists, parents, and citizens must move the popular conception of human evolution and human variation past the days of Blumenbach and Darwin. To do so means to question not just what we think we know about ourselves but what we think we know about everything around us too. Being so familiar and so widely adored, dogs have significant potential to untether racism from evolutionary biology, for good. Toward that end, we showed that the categories we impose on humans and dogs are different in important ways, and that the comparison lends no science to racism. Equating the differences between two human beings to the idealized differences between a greyhound and a bulldog is the province of poetry or prejudice, not science. 


\section{Acknowledgements}

We are grateful to the six reviewers and the editor at Evolutionary Anthropology whose feedback inspired us to improve upon an earlier version of this paper. Thanks to David Upegui and David Fastovsky for leading us to the education literature.

\section{Authors' contributions}

All authors wrote the paper. HLN and HMD co-led the effort. All authors read and approved the final manuscript.

\section{Funding}

Financial assistance for publication provided by the University of Rhode Island and the University of Cincinnati.

Availability of data and materials

Not applicable

\section{Competing interests}

The authors declare that they have no competing interests.

\section{Glossary}

AMOVA-analysis of molecular variance is a method to investigate population structure using molecular data. While $\mathrm{F}_{\mathrm{ST}}$ relies on allele frequencies, AMOVA also incorporates information about the genetic distance between haplotypes (Excoffier et al. 1992)

$\mathrm{F}_{\mathrm{ST}}$-a measure of genetic differentiation among subpopulations based on allele frequencies. $\mathrm{F}_{\mathrm{ST}}$ is a measure of the reduction of heterozygosity in a subpopulation relative to heterozygosity in the total population. $\mathrm{F}_{\mathrm{ST}}$ values of 0 indicate that individuals in a population are mating at random (there is no substructure), while an $\mathrm{F}_{\mathrm{ST}}$ value of 1 indicates complete substructure (subpopulations are completely differentiated on the basis of allele frequencies)

Genotype-the combination of alleles inherited from each parent at a particular genetic locus

Haplotype-a set of DNA variants inherited together as a single unit

Hardy-Weinberg equilibrium-a statistical test to determine if a genetic variant in a specific population is currently undergoing strong evolutionary forces such as selection or genetic drift. To be "in" Hardy-Weinberg equilibrium means that the allele frequencies of are remaining the same from generation to generation and evolution is not occurring at that locus

Heritability and Heritable traits-Heritability is a statistic used to estimate the amount of variation in a phenotypic trait that can be attributed to genetic variation between individuals in a population. Heritability explains the proportion of variation in a trait that cannot be explained by environmental or random factors. A common misconception about heritability statistics is that they can be used to explain the proportion of an individual's phenotype that is determined by genetics. In other words, if the heritability of a trait (say height) is 0.40 , this does not mean that $40 \%$ of an individual's height is determined by genetics and $60 \%$ by environment. Instead, this means that $40 \%$ of the variation in height within a particular population can be explained by genetic factors

Heterozygosity - the state of possessing two non-identical copies of an allele, inherited from each parent

Homozygosity-the state of possessing two identical copies of an allele, inherited from each parent

kya-thousands of years

Linkage-co-segregation (co-inheritance) of two or more alleles either due to physical location on the chromosome or the distribution of allele frequencies in the population

Locus (plural loci) - a physical location on the chromosome which usually represents the position of a gene or portion of a gene

Microsatellite-often referred to as short tandem repeats (STRs), these are small pieces of DNA that mutate rapidly and are useful to measure differences within and between groups

Mutualism-a symbiotic relationship that benefits both parties

mya-millions of years

Phenotype-the observed, physical properties of an organism, brought about by a combination of genetic and environmental factors

Population structure-occurs when a larger population contains multiple sub-populations, with varying degrees of gene flow occurring between them

Racialism - "the empirically false scientific idea that the human species can be naturally partitioned into a reasonably small number of reasonably distinct groups" (Marks 2017; p. 50)

Racism - "the morally corrupt political idea that natural human groups are differently endowed, are rankable and differently entitled on such a basis, and that consequently individual people ought to be judged on the basis of their membership in such groups, rather than on the basis of their own properties, abilities, achievements, or rights" (Marks 2017; p. 50)

Single nucleotide polymorphism (SNP) - genetic variation at a single base (i.e. A, C, G, or T) in the genome

Standard deviation-a way to quantify the amount of variation or dispersion of a dataset

Structure-a computer program that employs a model-based clustering algorithm to infer population structure using multi-locus genotype data. Briefly, for a user-defined value of $k$ (number of clusters) structure will find the most likely way to divide individuals in $k$ clusters based on their genotypes. Structure is also able to identify "admixed" individuals who have membership in more than one cluster (Pritchard et al. 2000) 


\section{Author details}

${ }^{1}$ Department of Anthropology, University of Cincinnati, Cincinnati, $\mathrm{OH}, \mathrm{USA}$. 2 Department of Internal Medicine/Section on Molecular Medicine, Center for Precision Medicine, Wake Forest School of Medicine, Winston-Salem, NC, USA. ${ }^{3}$ Department of Anthropology, University of Michigan, Ann Arbor, MI, USA. ${ }^{4}$ Department of Anthropology, The Pennsylvania State University, University Park, PA, USA. ${ }^{5}$ Department of Sociology and Anthropology, University of Rhode Island, Kingston, RI, USA.

Received: 18 April 2019 Accepted: 30 June 2019

Published online: 09 July 2019

\section{References}

Adhikari K, Fuentes-Guajardo M, Quinto-Sánchez M, Mendoza-Revilla J, Camilo Chacón-Duque J, Acuña-Alonzo V, et al. A genome-wide association scan implicates DCHS2, RUNX2, GLI3, PAX1 and EDAR in human facial variation. Nat Commun. 2016;7:11616.

Adhikari K, et al. A GWAS in Latin Americans highlights the convergent evolution of lighter skin pigmentation in Eurasia. Nat Commun. 2019;10:358.

American Association of Physical (Biological) Anthropologists. AAPA statement on race and racism. http://physanth.org/about/position-statements/ aapa-statement-race-and-racism-2019/. Accessed 10 June 2019.

American Kennel Club. www.akc.org. Accessed 5 Apr 2019.

American Society of Human Genetics. ASHG denounces attempts to link genetics and racial supremacy. Am J Hum Genet. 2018;103:636.

Bamshad MJ, Wooding S, Watkins WS, Ostler CT, Batzer MA, Jorde LB. Human population genetic structure and inference of group membership. Am J Hum Genet. 2003;72:578-89.

Beleza S, Johnson NA, Candille SI, Absher DM, Coram MA, Lopes J, et al. Genetic architecture of skin and eye color in an African-European admixed population. PLoS Genet. 2013;9(3):e1003372.

Bolnick D. Individual ancestry inference and the reification of race as a biologically phenomenon. In: Koenig BA, Lee SS, Richardson SS, editors. Revisiting race in a genomic age. Rutgers University Press: New Brunswick; 2008. p. 70-85.

Botigué LR, Song S, Scheu A, Gopalan S, Pendleton AL, Oetjens M, et al. Ancient European dog genomes reveal continuity since the Early Neolithic. Nat Commun. 2017:8:16082.

Boulter AC, Quinlan J, Miró-Herrans AT, Pearson LN, Todd NL, HEAT Steering Committee, Gravlee CC, Mulligan CJ. Interaction of Alu polymorphisms and novel measures of discrimination in association with blood pressure in African Americans living in Tallahassee, Florida. Hum Biol. 2015;87(4):295-305.

Boyko AR, Boyko RH, Boyko CM, Parker HG, Castelhano M, Corey L, et al. Complex population structure in African village dogs and its implications for inferring dog domestication history. Proc Nat Acad USA. 2009;106(33):13903-8.

Brace CL. "Race" is a four-letter word: the genesis of the concept. New York: Oxford University Press; 2005.

Cadieu E, Neff MW, Quignon P, Walsh K, Chase K, Parker HG, et al. Coat variation in the domestic dog is governed by variants in three genes. Science. 2009;326:150-3.

Candille SI, Absher DM, Beleza S, Bauchet M, McEvoy B, Garrison NA, et al. Genome-wide association studies of quantitatively measured skin, hair, and eye pigmentation in four European populations. PLOS ONE. 2012;7(10):e48294.

Castle WE. Dog crosses and human crosses: a review. J Hered. 1942;33(7):249-52.

Chase K, Carrier DR, Adler FR, Jarvik T, Ostrander EA, Lorentzen TD, Lark KG. Genetic basis for systems of skeletal quantitative traits: principal component analysis of the canid skeleton. Proc Nat Acad Sci USA. 2002;99:9930-5.

Crawford NG, Kelly DE, Hansen MEB, Beltrame MH, Fan S, Bowman SL, et al. Loci associated with skin pigmentation identified in African populations. Science. 2017;358(6365):eaan8433.

Dannemann M, Kelso J. The contribution of Neanderthals to phenotypic variation in modern humans. Am J Hum Genet. 2017;101(4):578-89.

Dar-Nimrod I, Heine SJ. Genetic essentialism: on the deceptive determinism of DNA. Psychol Bull. 2011;137(5):800-18.
Darwin C. Descent of man. London: John Murray; 1871.

Dobzhansky T. A review of some fundamental concepts and problems of population genetics. Cold Spring Harb Symp Quant Biol 1955;20:1-15.

Dobzhansky T. Mankind Evolving: The Evolution of the Human Species. New Haven CT:Yale University Press; 1962.

Donovan BM. Learned inequality: racial labels in the biology curriculum can affect the development of racial prejudice. J Res Sci Teach. 2017;54(3):379-411.

Donovan BM, Semmens R, Keck P, Brimhall E, Busch KC, Weindling M, Duncan A, Stuhlsatz M, Bracey ZB, Bloom M, Kowalski S, Salazar B. Toward a more humane genetics education: learning about the social and quantitative complexities of human genetic variation research could reduce racial bias in adolescent and adult populations. Sci Educ. 2019;2019:1-32.

Edwards AWF. Human genetic diversity: Lewontin's fallacy. BioEssays. 2003;25:798-801.

Eriksson N, Macpherson JM, Tung JY, Hon LS, Naughton B, Saxonov S, et al. Web-based, participant-driven studies yield novel genetic associations for common traits. PLoS Genet. 2010;6(6):1-20.

Excoffier L, Smouse PE, Quattro JM. Analysis of molecular variance inferred from metric distances among DNA haplotypes: application to human mitochondrial DNA restriction data. Genetics. 1992;131(2):479-91.

Frantz LAF, Mullin VE, Pionnier-Capitan M, Lebrasseur O, Ollivier M, Perri A, Linderholm A, Mattiangeli V, Teasdale MD, Dimopoulos EA, Tresset A, Duffraisse M, McCormick F, Bartosiewicz L, Gál E, Nyerges EA, Sablin MV, Bréhard S, Mashkour M, Bălăşescu A, Gillet B, Hughes S, Chassaing O, Hitte C, Vigne J-D, Dobney K, Hänni C, Bradley DG, Larson G. Genomic and archaeological evidence suggest a dual origin of domestic dogs. Science. 2016;352(6290):1228-31.

Fryar CD, Gu Q, Ogden CL, Flegal KM. Anthropometric reference data for children and adults: United States, 2011-2014. National Center for Health Statistics. Vital Health Stat. 2016;3(39):1-46.

Gibbons A. Shedding light on skin color. Science. 2014;346(6212):934-6.

Gravlee L. How race becomes biology: embodiment of social inequality. Am J Phys Anthropol. 2009;39(1):47-57.

Gravlee CC, Non AL, Mulligan CJ. Genetic ancestry, social classification, and racial inequalities in blood pressure in Southeastern Puerto Rico. PLoS ONE. 2009;4(9):e6821. https://doi.org/10.1371/journal.pone.0006821.

Guenther CA, Tasic B, Luo L, Bedell MA, Kingsley DM. A molecular basis for classic blond hair color in Europeans. Nat Genet. 2014;46:748-52.

Haldane JBS. The argument from animals to men: an examination of its validity for anthropology. J R Anthropol Inst G B Irel. 1956:86(2):1-14.

Hardimon MO. The idea of a scientific concept of race. J Philos Res 2012:37:249-82

Harkinson J. Meet the white nationalist trying to ride the trump train to lasting power. Mother Jones 27 October 2016. https://www.motherjones.com/ politics/2016/10/richard-spencer-trump-alt-right-white-nationalist/. Accessed 5 Apr 2019.

Harrington P. No mongrels need apply. Minn Rev. 2009;73:219-30.

Hedges SB, Marin J, Suleski M, Paymer M, Kumar S. Tree of life reveals clock-like speciation and diversification. Mol Biol Evol. 2015;32(4):835-45.

Higham T, Douka K, Wood R, Ramsey CB, Brock F, Basell L, et al. The timing and spatiotemporal patterning of Neanderthal disappearance. Nature. 2014;512:306-9.

Hradecka L, Bartos L, Svobodova I, Sales J. Heritability of behavioural traits in domestic dogs: a meta-analysis. Appl Anim Behav Sci. 2015;170:1-13.

Hunley KL, Healy ME, Long JC. The global pattern of gene identity variation reveals a history of long-range migrations, bottlenecks, and local mate exchange: implications for biological race. Am J Phys Anthropol. 2009;139:35-46.

Irion DN, Schaffer AL, Famula TR, Eggleston ML, Hughes SS, Pedersen NC. Analysis of genetic variation in 28 dog breed populations with 100 microsatellite markers. J Hered. 2003;94(1):81-7.

Jackson JP Jr, Depew DJ. Darwinism, democracy, and race: American anthropology and evolutionary biology in the twentieth century. New York: Routledge; 2017.

Jones P, Chase K, Martin A, Davern P, Ostrander EA, Lark KG. Single-nucleotidepolymorphism-based association mapping of dog stereotypes. Genetics. 2008;179(2):1033-44.

Kaelin CB, Barsh GS. Genetics of pigmentation in dogs and cats. Annu Rev Anim Biosci 2013;1(1):125-56. 
Kaplan JM, Winther RG. Realism, antirealism, and conventionalism about race. Philos Sci 2014;81(5):1039-52.

Kenny EE, Timpson NJ, Sikora M, Yee MC, Moreno-Estrada A, Eng C, Huntsman S, Burchard EG, Stoneking M, Bustamante CD, Myles S. Melanesian blond hair is caused by an amino acid change in TYRP1. Science. 2012;336(6081):554.

Koenig BA, Soo-Jin Lee S, Richardson SS. Revisiting race in a genomic age. New Brunswick: Rutgers University Press; 2008.

Koskinen MT. Individual assignment using microsatellite DNA reveals unambiguous breed identification in the domestic dog. Anim Genet. 2003;34(4):297-301.

Kuhlwilm M, Gronau I, Hubisz MJ, de Filippo C, Prado-Martinez J, Kircher M, et al. Ancient gene flow from early modern humans into Eastern Neanderthals. Nature. 2016;530(7591):429.

Lamason RL, Mohideen MA, Mest JR, Wong AC, Norton HL, Aros MC, et al. SLC24A5, a putative cation exchanger, affects pigmentation in zebrafish and humans. Science. 2005;310(5755):1782-6.

Lawson DJ, Van Dorp L, Falush D. A tutorial on how not to over-interpret STRU CTURE and ADMIXTURE bar plots. Nat Commun. 2018;9:3258.

Lee TW, Grogan KE, Liepkalns JS. Making evolution stick: using sticky notes to teach the mechanisms of evolutionary change. Evol Educ Outreach 2017;10:11.

Leroy G. Genetic diversity, inbreeding and breeding practices in dogs: results from pedigree analyses. Vet J. 2011;189:177-82.

Lewontin RC. The apportionment of human diversity. Evol Biol. 1972;6:381-98.

Li JZ, Absher DM, Tang H, Southwick AM, Casto AM, Ramachandran S, Cann HM, Barsh GS, Feldman M, Cavalli-Sforza LL, Myers RM. Worldwide human relationships inferred from genome-wide patterns of variation. Science 2008;319 (5866):1100-4.

Livingstone FB. On the nonexistence of human races. Curr Anthropol. 1962:3:279-81.

Lombardo PA. Miscegenation, eugenics, and racism: historical footnotes to loving v. virginia. UC Davis L Rev 1987-1988;21:421-52.

Marks J. Ten facts about human variation. In: Muehlenbein MP, editor. Human evolutionary biology. Cambridge: Cambridge University Press; 2010.

Marks J. The origins of anthropological genetics. Curr Anthropol. 2012a;53:S161-72.

Marks J. Why be against Darwin? Creationism, racism, and the roots of anthropology. Yrbk Phys Anthropol. 2012b;55:95-104.

Marks J. Essay review: solving the riddle of race. Stud Hist Philos Biol Biomed Sci. 2016;59:161-4.

Marks J. Is science racist?. Malden: Polity Press; 2017.

Martin AR, Lin M, Granka JM, Myrick JW, Liu X, Sockell A, et al. An unexpectedly complex architecture for skin pigmentation in humans. Cell. 2017;171:1340-53.

McLean S-A. Social problems, structural issues, and unsettling science. Am Anthropol. 2019;121(2):480-1.

Mech LD, Barber-Meyer SM, Erb J. Wolf (Canis lupus) generation time and proportion of current breeding females by age. PLOS ONE. 2016;11(6):e0156682.

Medland SE, Nyholt DR, Painter JN, McEvoy BP, McRae AF, Zhu G, et al. Common variants in the trichohyalin gene are associated with straight hair in Europeans. Am J Hum Genet. 2009:85(5):750-5.

Mehrkam LR, Wynne CDL. Behavioral differences among breeds of domestic dogs (Canis lupus familiaris): current status of the science. Appl Anim Behav Sci. 2014;155:12-27.

Montagu A. Man's most dangerous myth: the fallacy of race. New York: Meridian; 1942.

Nan H, Kraft P, Qureshi AA, Guo Q, Chen C, Hankinson SE, Hu FB, et al. Genomewide association study of tanning phenotype in a population of European ancestry. J Invest Dermatol. 2009;129:2250-7.

Norton HL, Kittles RA, Parra E, McKeique P, Mao X, Cheng K, et al. Genetic evidence for the convergent evolution of light skin in Europeans and East Asians. Mol Biol Evol. 2007:24(3):710-22.

Novembre J. Pritchard, Stephens, and Donnelly on population structure. Genetics. 2016;204:391-3.

Parker HG, Kim LV, Sutter NB, Carlson S, Lorentzen TD, Malek TB, Johnson GS, DeFRance HB, Ostrander EA, Kruglyak L. Genetic structure of the purebred domestic dog. Science. 2004;304:1 160-4.
Parker HG, Harris A, Dreger DL, Davis BW, Ostrander EA. The bald and the beautiful: hairlessness in domestic dog breeds. Phil Trans R Soc B. 2017:372:20150488.

Pritchard JK, Stephens M, Donnelly P. Inference of population structure using multilocus genotype data. Genetics. 2000;155(2):945-59.

Quillen EE, Bauchet M, Bigham AW, Delgado-Burbano ME, Faust FX, Klimentidis $Y C$, et al. OPRM1 and EGFR contribute to skin pigmentation differences between indigenous Americans and Europeans. Hum Genet. 2012:131(7):1073-80.

Quillen EE, Norton HL, Parra EJ, et al. Shades of complexity: new perspectives on the evolution and genetic architecture of human skin. Am J Phys Anthropol. 2019;168(S67):4-26.

Quinlan J, Pearson LN, Clukay CJ, Mitchell MM, Boston Q, Gravlee CC, Mulligan CJ. Genetic loci and novel discrimination measures associated with blood pressure variation in African Americans living in Tallahassee. PLoS ONE. 2016;11(12):e0167700. https://doi.org/10.1371/journ al.pone.0167700.

Racimo F, Sankararaman S, Nielsen R, Huerta-Sanchez E. Evidence for archaic adaptive introgression in humans. Nat Rev Genet. 2015;16(6):359-71.

Reich D, Patterson N, Kircher M, Delfin F, Nandineni MR, Pugach I, et al. Denisova admixture and the first modern human dispersals into Southeast Asia and Oceania. Am J Hum Genet. 2011;89(4):516-28.

Relethford J. Race and global patterns of phenotypic variation. Am J Phys Anthropol. 2009:39(1):16-22.

Rimbault M, Beale HC, Schoenebeck JJ, Hoopes BC, Allen JJ, Kilroy-Glynn P, Wayne RK, Sutter NB, Ostrander EA. Derived variants at six genes explain nearly half of size reduction in dog breeds. Genome Res. 2013;23(12): 1985-95.

Rosenberg NA, Pritchard JK, Weber JL, Cann HM, Kidd KK, Zhivotovsky LA, Feldman MW. Genetic structure of human populations. Science. 2002;298:2381-5.

Santos RV, Fry PH, Monteiro S, Maio MC, Rodrigues JC, Bastos-Rodrigues $\mathrm{L}$, Pena SDJ. Color, race, and genomic ancestry in Brazil: dialogues between anthropology and genetics. Curr Anthropol. 2009:50(6):787-819.

Sarich and Miele. Race: the reality of human differences. Cambridge: Westview Press; 2004.

Scott JP, Fuller JL. Genetics and the social behavior of dogs. Chicago: University of Chicago Press; 1965.

Shannon LM, Boyko RH, Castelhano M, Corey E, Hayward JJ, McLean C, et al. Genetic structure in village dogs reveals a Central Asian domestication origin. Proc Natl Acad Sci USA. 2015:112(44):13639-44.

Shriver MD, Parra EJ, Dios S, Bonilla C, Norton H, Jovel C, et al. Skin pigmentation, biogeographical ancestry and admixture mapping. Hum Genet. 2003;112(4):387-99.

Simonti CN, Vernot B, Bastarache L, Bottinger E, Carrell DS, Chisholm RL, et al. The phenotypic legacy of admixture between modern humans and Neandertals. Science. 2016;351(6274):737-41.

Sims M, Diez-Roux AV, Dudley A, Gebreab S, Wyatt SB, Bruce MA, James SA, Robinson JC, Williams DR, Taylor HA. Perceived discrimination and hypertension among African Americans in the Jackson Heart Study. Am J Public Health. 2012;102(Suppl 2):S258-65. https://doi.org/10.2105/ A.JPH.2011.300523.

Smith SL. Single (sub)species then and now: an examination of the nonracial perspective of C. Loring Brace. Am J Phys Anthropol. 2018;165:104-25.

Snipp CM. Racial measurement in the American census: past practices and implications for the future. Ann Rev Sociol. 2003;29:563-88.

Stone HR, McGreevy PD, Starling MJ, Forkman B. Associations between domestic-dog morphology and behaviour scores in the dog mentality assessment. PLoS ONE. 2016;11(2):1-14.

Sulem P, Gudbjartsson DF, Stacey SN, Helgason A, Rafnar T, Magnusson KP, et al. Genetic determinants of hair, eye and skin pigmentation in Europeans. Nat Genet. 2007;39(12):1443-52.

Sulem P, Gudbjartsson DF, Stacey SN, Helgason A, Rafnar T, Jakobsdottir M, et al. Two newly identified genetic determinants of pigmentation in Europeans. Nat Genet. 2008;40(7):835-7.

Sussman RW. The myth of race: The troubling persistence of an unscientific idea. Cambridge: Harvard University Press; 2014.

Sutter NB, Bustamante CD, Chase K, Gray MM, Zhao K, Zhu L, Padhukasahasram $B$, et al. A single IGF1 allele is a major determinant of small size in dogs. Science. 2007;316(5821):112-5. 
Sutter NB, Mosher DS, Gray MM, Ostrander EA. Morphometrics within dog breeds are highly reproducible and dispute Rensch's rule. Mamm Genome. 2008;19(10-12):713-23.

Thalmann O, Shapiro B, Cui P, Schuenemann VJ, Sawyer SK, Greenfield $\mathrm{DL}$, Germonpré $\mathrm{MB}$, et al. Complete mitochondrial genomes of ancient canids suggest a European origin of domestic dogs. Science. 2013;342(6160):871-4

The 1000 Genomes Project Consortium. A global reference for human genetic variation. Nature. 2015:526(7571):68-74.

Torres JB, Colón GAT. Racial experience as an alternative operationalization of race. Hum Biol. 2015;87(4):306-13.

Townshend E. Darwin's dogs: how Darwin's pets helped form a world-changing theory of evolution. London: Frances Lincoln; 2009.

United States Census Bureau. www.census.gov. Accessed 5 Apr 2019.

Valverde P, Healy E, Jackson I, Rees JL, Thody AJ. Variants of the melanocytestimulating hormone receptor gene are associated with red hair and fair skin in humans. Nat Genet. 1995;11(3):328-30.

Vance M. Biology teaching in a racist society. In: Gill D, Levidow L, editors. Antiracist science teaching. London: Free Association Books; 1987.

Vernot B, Tucci S, Kelso J, Schraiber JG, Wolf AB, Gittelman RM, et al. Excavating Neandertal and Denisovan DNA from the genomes of Melanesian individuals. Science. 2016;352(6282):235-9.

Vilà C, Savolainen P, Maldonado JE, Amorim IR, Rice JE, Honeycutt RL, Crandall KA, Lundeberg J, Wayne RK. Multiple and ancient origins of the domestic dog. Science. 1997;276(5319):1687-9.

vonHoldt BM, Pollinger JP, Lohmueller KE, Han E, Parker HG, Quignon P, Degenhardt JD, Boyko AR, Earl DA, Auton A, Reynolds A, Bryc K, Brisbin A, Knowles JC, Mosher DS, Spady TC, Elkahloun A, Geffen E, Pilot M, Jedrzejewski W, Greco C, Randi E, Bannasch D, Wilton A, Shearman J, Musiani M, Cargill M, Jones PG, Qian Z, Huang W, Ding Z-L, Zhang Y, Bustamante CD, Ostrander EA, Novembre J, Wayne RK. Genome-wide SNP and haplotype analyses reveal a rich history underlying dog domestication. Nature. 2010;464:898-902.

Wade N. A troublesome inheritance: genes, race and human history. New York: Penguin; 2014.
Wagner JK, Yu J-H, Ifekwunigwe JO, Harrell TM, Bamshad MJ, Royal CD. Anthropologists' views on race, ancestry, and genetics. Am J Phys Anthropol. 2017;162(2):318-27.

Wang GD, Zhai W, Yang HC, Wang L, Zhong L, Liu YH, et al. Out of southern East Asia: the natural history of domestic dogs across the world. Cell Res. 2016;26(1):21-33.

Weaver H. "Becoming in kind": race, class, gender, and nation in cultures of dog rescue and dogfighting. Am Q. 2013;65(3):689-709.

Weiss KM. The tales genes tell (or not): a century of exploration. Am J Phys Anthropol. 2018;165:741-53.

Weiss K, Fullterton SM. Racing around, getting nowhere. Evol Anthropol. 2005;14:165-9.

Weiss K, Lambert B. Does history matter? Evol Anthropol. 2010;19:92-7.

Weiss K, Lambert B. When the time seems ripe: eugenics, the annals, and the subtle persistence of typological thinking. Ann Hum Genet. 2011;75:334-43.

Weiss K, Lambert B. What type of person are you? Cold Spring Harb Perspect Biol. 2014;6:1-14.

Weiss K, Long JC. Non-Darwinian estimation: my ancestors, my genes'ancestors. Genome Res. 2009;19:703-10.

Westgate GE, Ginger RS, Green MR. The biology and genetics of curly hair. Exp Dermatol. 2017;26(6):483-90.

Wood AR, Esko T, Yang J, Vedantam S, Pers TH, Gustafsson S, et al. Defining the role of common variation in the genomic and biological architecture of adult human height. Nat Genet. 2014;46(11):1173-86.

Yudell M, Roberts D, DeSalle R, Tishkoff S. Taking race out of human genetics. Science. 2016;351(6273):564-5.

Zack N. The fluid symbol of mixed race. Hypatia. 2010;25(4):875-90.

\section{Publisher's Note}

Springer Nature remains neutral with regard to jurisdictional claims in published maps and institutional affiliations.
Ready to submit your research? Choose BMC and benefit from:

- fast, convenient online submission

- thorough peer review by experienced researchers in your field

- rapid publication on acceptance

- support for research data, including large and complex data types

- gold Open Access which fosters wider collaboration and increased citations

- maximum visibility for your research: over $100 \mathrm{M}$ website views per year

At BMC, research is always in progress.

Learn more biomedcentral.com/submissions 